\title{
Preoperative carcinoembryonic antigen levels correlated with postoperative pathological staging in bronchial carcinoma
}

\author{
JOSEPH F PAONE, A KARDANA, GORDON T ROGERS, JANARDEN DHASMANA, \\ AND K JEYASINGHAM
}

From the Department of Surgery, Johns Hopkins Hospital, Baltimore, Maryland, USA, Department of Medical Oncology, Charing Cross Hospital, London, and Department of Thoracic Surgery, Frenchay Hospital, Bristol

\begin{abstract}
Serum carcinoembryonic antigen (CEA) levels were obtained before operation in 214 patients undergoing diagnostic tests for suspected bronchial carcinoma, and the results correlated with the postoperative, pathological stage of disease. Positive CEA levels $(>10 \mathrm{ng} / \mathrm{ml})$ were observed in $40 \%(8 / 20)$ of stage $1,58.5 \%(31 / 53)$ of stage $2,85 \cdot 2 \%(69 / 81)$ of stage 3 , and $92.3 \%(24 / 26)$ of stage 4 patients with bronchial carcinoma. Furthermore, the mean CEA levels increased with stage of disease, and the differences between mean levels were found to be significant in stages 1 and 2 versus 3 and $4(\mathrm{p}<0.001)$. This suggests a positive correlation between the preoperative CEA level and tumour burden defined by pathological staging. When the results were compared with the histological type of lung carcinoma, CEA elevations occurred most frequently with adenocarcinoma, followed by undifferentiated and squamous cell carcinoma, reflecting perhaps the origin of this oncofetal antigen from the endodermally derived bronchial mucosa. These data indicate that preoperative serum CEA levels quantitatively reflect the extent of tumour assessed pathologically at operation and confirm the potential usefulness of this antigen as a biological tumour marker in the management of bronchial neoplasms.
\end{abstract}

Carcinoembryonic antigen (CEA) is a highly antigenic glycoprotein which is gaining clinical acceptance as a biological tumour marker for an increasing number of neoplastic disorders. In the case of bronchial carcinoma, a number of clinical studies in the past 10 years have demonstrated elevations of serum levels of CEA in patients with this neoplasm. ${ }^{1-5}$

Recent investigations have begun to define the precise role that the measurement of CEA may assume in the management of patients with bronchial neoplasms. Carcinoembryonic antigen determinations obtained before operation and sequentially after pulmonary resection have been shown to be potentially useful in the determination of prognosis and operability, ${ }^{\circ}$ in the

Presented at the Annual Meeting of the Society of Thoracic and Cardiovascular Surgeons of Great Britain and Ireland, Coventry, 13-14 September 1979.

Address for reprint requests: Dr JF Paone, Department of Surgery, Johns Hopkins Hospital, 601 North Broadway, Baltimore, Maryland 21205, USA. definition of the extent of disease for adjuvant ? therapy, ${ }^{7}$ and as a monitor for recurrent bron- $\frac{5}{3}$ chial carcinoma after pulmonary resection. ${ }^{89}$

As a prerequisite to the use of CEA levels in the management of patients with bronchial carcinoma, it is imperative to determine how well serum CEA determinations quantitatively $\frac{D}{2}$ reflect the extent of tumour determined pathologically at operation. The present study was o begun to define more precisely the correlation $N$ between preoperative CEA levels and the histo- N logical type and extent of bronchial carcinoma $\mathrm{C}$ determined by postsurgical pathological staging methods.

PATIENT POPULATION

Serum samples for CEA analysis were obtained $\frac{T}{\circ}$ hefore invasive diagnostic procedures from all $\vec{D}$ patients admitted to the Thoracic Surgery Service, $\frac{\stackrel{\rho}{\Phi}}{\Phi}$ Frenchay Hospital, Bristol with suspected bron- $\varrho$ chial carcinoma. Patients found to have significant medical illness other than bronchialo 
carcinoma were excluded. Of 214 patients included in this study, 180 were found to have bronchial carcinoma and 34 active benign pulmonary disease, principally pneumonia, empyema, or tuberculosis.

\section{CEA ASSAY}

Blood samples for analysis were drawn by venepuncture, allowed to clot, centrifuged, and stored at $-20^{\circ} \mathrm{C}$ until analysed for CEA at the Charing Cross Hospital, London. The assay employed is an automated indirect radioimmunoassay using Enzacryl linked anti-CEA antiserum and ${ }^{125} \mathrm{I}$ labelled purified CEA. ${ }^{10}$ The anti-CEA antiserum was raised to immunopurified CEA-2B. ${ }^{11}$ The mean serum CEA level for this assay has been determined to be $5 \mathrm{ng} / \mathrm{ml}$ in normal, healthy volunteers and the upper limit of normal set at $10 \mathrm{ng} / \mathrm{ml}$ (mean level $+2 \mathrm{SD}$ ).

\section{STAGING METHODS}

All patients with carcinoma underwent postsurgical pathological staging using a variety of preoperative anatomical techniques and the results of operation. Chest radiographs with selective tomography and liver function tests were obtained and bronchoscopy and biopsy performed in each case. Radioisotopic scans were obtained if the serum alkaline phosphatase was found to be elevated or if clinical evidence of metastases was present. The surgical procedures employed were as follows: 122 patients $(57 \%)$ underwent pulmonary resection; 42 patients $(19.6 \%)$ were explored and found to have unresectable tumours; $25(11.6 \%)$ underwent bronchoscopy with or without mediastinoscopy and were found to have benign disease, or carcinoma with involvement of the carinal or superior mediastinal nodes; and $25(11.6 \%)$ were staged by peripheral node biopsy or scans and found to have distant metastases.

During operation, radical lymph node dissection was uniformly performed in resectable cases. Nodes were identified and submitted separately at all levels. In cases found to be unresectable. biopsies were obtained from the primary tumour and involved adjacent structures or mediastinal nodes. The final staging system (table 1) was a modification of the TNM system currently proposed by the American Joint Committee for Cancer Staging. ${ }^{12}$

\section{Results}

The preoperative CEA levels observed in the 214 patients studied are shown in the figure.
Table 1 Preoperative CEA elevations in patients with bronchial carcinoma correlated with pathological stage of disease

\begin{tabular}{|c|c|c|}
\hline Stage grouping & $\begin{array}{l}\text { Number } \\
\text { of patients }\end{array}$ & $\begin{array}{l}\text { Incidence of positive } \\
\text { CEA levels }(>10 \mathrm{ng} / \mathrm{ml})\end{array}$ \\
\hline $\begin{array}{l}\text { 1. Stage } 1 \\
\mathrm{~T}_{1} \mathrm{~N}_{0} \mathrm{M}_{0}\end{array}$ & 20 & $8 / 20(40 \%)$ \\
\hline $\begin{array}{l}\text { 2. Stage } 2 \\
\mathbf{T}_{1} \mathbf{N}_{1} \mathbf{M}_{0} \\
\mathbf{T}_{2} \mathbf{N}_{0} \mathbf{M}_{0} \\
\mathbf{T}_{2} \mathbf{N}_{1} \mathbf{M}_{0}\end{array}$ & 53 & $31 / 53(58 \cdot 5 \%)$ \\
\hline $\begin{array}{l}\text { 3. Stage } 3 \\
T_{3} \mathbf{N}_{0} \mathbf{M}_{0} \\
T_{3} \mathbf{N}_{1} \mathbf{M}_{0} \\
\mathbf{N}_{2} \text { with any } T \mathbf{M}_{0}\end{array}$ & 81 & $69 / 81(85 \cdot 2 \%)$ \\
\hline $\begin{array}{l}\text { 4. Stage } 4 \\
\mathbf{M}_{1} \text { with any } \mathrm{T} \text { or } \mathrm{N} \\
\text { Total series }\end{array}$ & 26 & $24 / 26(92 \cdot 3 \%)$ \\
\hline with carcinoma & 180 & $132 / 180(73 \cdot 3 \%)$ \\
\hline
\end{tabular}

The mean serum CEA levels measured in each pathological stage of bronchial carcinoma are summarised in table 2. Differences between the mean CEA levels of each stage were statistically significant $(\mathrm{p}<0.001)$, with the exception of stage 1 versus stage 2 .

Using $10 \mathrm{ng} / \mathrm{ml}$ as the level above which significant CEA elevations occur when compared to normal control subjects, it was found that positive CEA levels were present in $40 \%(8 / 20)$ of stage $1,58.5 \%(31 / 53)$ of stage $2,85.2 \%(69 / 81)$ of stage 3 , and $92.3 \%(24 / 26)$ of stage 4 patients (table 1). The mean CEA level in the group studied with active benign pulmonary disease was $6.45 \pm 4.79 \mathrm{ng} / \mathrm{ml}$ (SD). The upper limit at which significant elevations occur when compared to this disease control group was, therefore, set at $16 \mathrm{ng} / \mathrm{ml}$ (mean level $+2 \mathrm{SD}$ ). When compared to the disease control group, significant CEA elevations $(>16 \mathrm{ng} / \mathrm{ml})$ were found in $25 \%$ $(5 / 20)$ of stage $1,35.9 \%(19 / 53)$ of stage $2,54.3 \%$ $(44 / 81)$ of stage 3 , and $73.1 \%(19 / 26)$ of stage 4 patients. When the results were correlated with the histological type of tumo: $r$ found at oper-

Table 2 Mean preoperative CEA levels ( \pm SEM) grouped according to the pathological stage of bronchial carcinoma

\begin{tabular}{lc}
\hline Group & Mean CEA level $(\mathrm{ng} / \mathrm{ml} \pm S E M)$ \\
\hline Benign active pulmonary & $6 \cdot 45 \pm 0 \cdot 83^{*}$ \\
2 Stage 1 & $10 \cdot 55 \pm 1 \cdot 79 \dagger$ \\
3 Stage 2 & $14 \cdot 77 \pm 1 \cdot 55 \dagger$ \\
4 Stage 3 & $25 \cdot 68 \pm 2 \cdot 20 \ddagger$ \\
5 Stage 4 & $61 \cdot 84 \pm 10 \cdot 57 \S$ \\
\hline
\end{tabular}

Significance using the unpaired Student $t$ test

$* p<0.25$ versus $1 ; p<0.001$ versus $2,3,4$

$\dagger$ NS

$\ddagger \mathrm{p}<0.001$ versus 1,2

$\S \mathrm{p}<0.001$ versus $1,2,3$ 


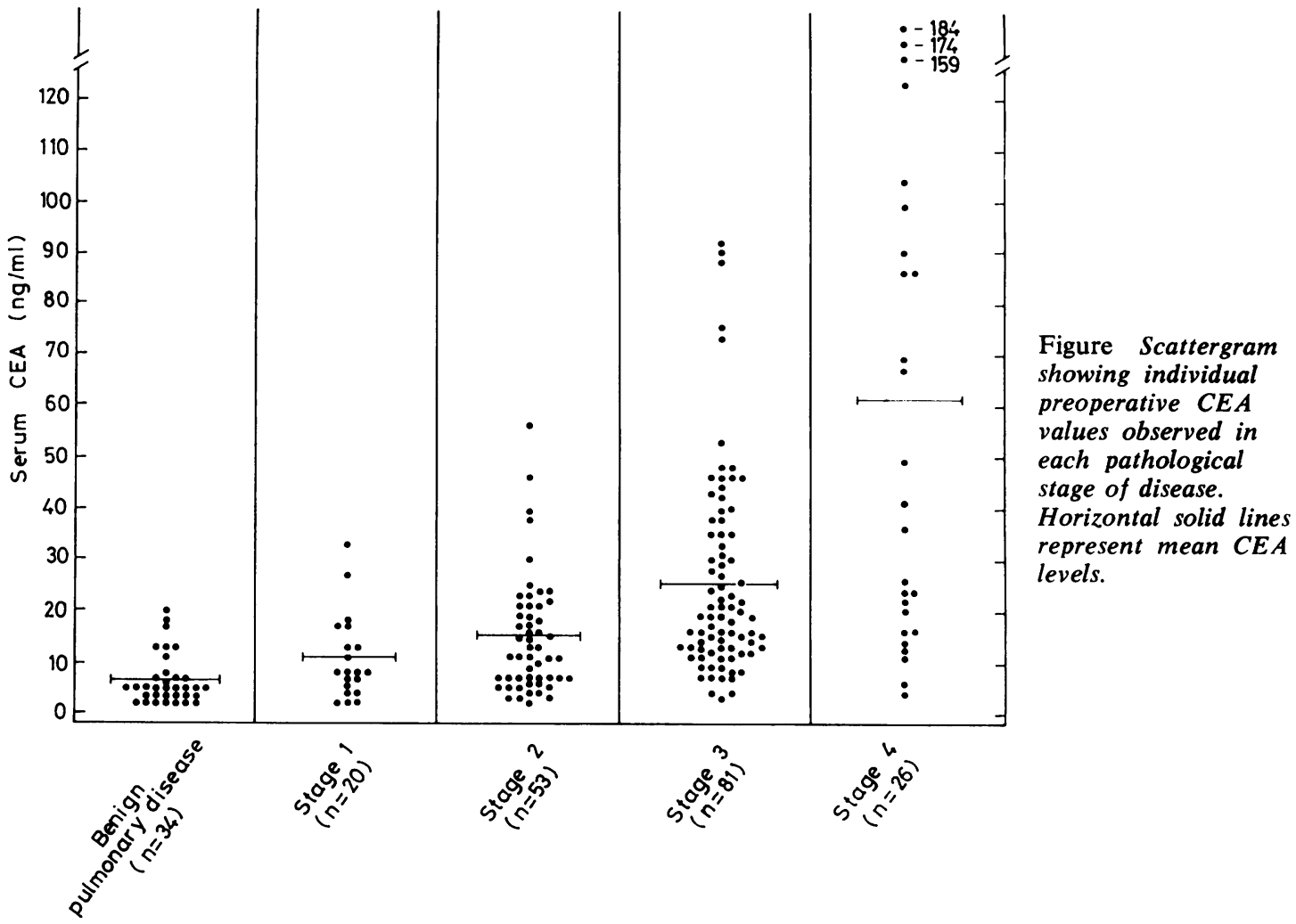

ation, CEA levels were found to be most frequently elevated in the presence of adenocarcinoma, followed by undifferentiated large and small cell carcinoma, and squamous cell carcinoma (table 3 ). Of the patients with benign, active, inflammatory pulmonary diseases, $20.6 \%$ (7/34) had significant elevations compared to normal control subjects. The overall incidence of preoperative CEA elevations $(>10 \mathrm{ng} / \mathrm{ml})$ observed in patients with bronchial carcinoma in this study was $73 \cdot 2 \%(132 / 180)$.

\section{Discussion}

There is increasing interest in the study of

Table 3 Preoperative CEA elevations grouped according to histological type of bronchial carcinoma found at operation

\begin{tabular}{lc}
\hline Histological type of tumour & $\begin{array}{l}\text { Incidence of CEA clevation } \\
(>10 \mathrm{ng} / \mathrm{ml})\end{array}$ \\
\hline 1 Adenocarcinoma & $19 / 22(86.4 \%)$ \\
2 Undifferentiated large cell & $20 / 27(74 \cdot 1 \%)$ \\
3 Undifferentiated small cell ("oat cell”) & $24 / 35(68 \cdot 6 \%)$ \\
4 Squamous carcinoma & $64 / 96(66 \cdot 7 \%)$ \\
5 Benign active pulmonary disease & $7 / 34(20.6 \%)$ \\
\hline
\end{tabular}

tumour biomarkers in the assessment and management of patients with bronchial carcinoma. Elevations of serum levels of carcinoembryonic antigen (CEA) have been observed in 50-80\% of patients with bronchial neoplasms, and recent studies have suggested specific uses for this marker in the management of lung cancer patients. ${ }^{6-9} 13$

Tormey et $a l^{14}$ have emphasised that a biological tumour marker should be capable of quantitatively measuring the "actual clinical or subclinical tumour burden of the host." The ability of CEA to do this in patients with bronchial carcinoma has been the object of several investigations. Dent et $a l^{7}$ reported a positive correlation between CEA levels and the extent of intrathoracic compared with extrathoracic disease in lung cancer patients referred for palliative therapy. Gropp et $a^{13}$ observed significantly higher CEA levels in patients with metastatic lung carcinoma than in those with local disease. Vincent et al ${ }^{15}$ could not initially demonstrate a relationship between CEA levels and the "tumour volume" present at necropsy in patients with advanced lung cancer, but later observed ${ }^{8}$ that serial CEA levels do parallel tumour recurrence 
and progression after pulmonary resection. Similarly, a large, recent series reported by Ford et $a l^{9}$ demonstrated that serial postoperative CEA determinations may effectively monitor the clinical course of bronchial carcinoma and the effects of treatment for metastatic disease.

Recently, Concannon et $a l,{ }^{6}$ in a study on the prognostic significance of preoperative CEA elevation in patients with bronchial carcinoma, noted a positive correlation between the incidence of CEA elevations (greater than $6 \mathrm{ng} / \mathrm{ml}$ ) and the postsurgical pathological stage of disease. Postsurgical pathological staging represents the best method currently available to assess the anatomical extent of disease in patients with bronchial carcinoma. ${ }^{12} 1617$ In Concannon's study of 149 patients significantly more were observed to have CEA elevations in stage 4 than in stages 1,2 , and $3(\mathrm{p}<0.01)$.

The object of the present study was to determine the precise correlation between preoperative CEA levels and the anatomical extent of bronchial carcinoma determined by pathological staging. Carcinoembryonic antigen elevations (defined as greater than $10 \mathrm{ng} / \mathrm{ml}$ ) were observed in $73.3 \%(132 / 180)$ of patients with all stages of bronchial carcinoma. The frequency with which CEA elevations were observed compared to both normal and disease control patients was found to increase with the increasing pathological stage of disease. Although overlap of individual CEA levels occurred between stages (fig), the mean preoperative CEA levels correlated positively with the pathological stages of disease. Furthermore, the differences between mean levels (table 2 ) were statistically significant for stages 1 and 2 versus 3 and $4(p<0.001)$. This suggests a strong positive correlation between the quantitative amount of CEA detected in serum and the anatomical extent of bronchial tumour determined by pathological staging.

When results were correlated with the histological type of bronchial carcinoma, CEA elevations were observed to occur most frequently with adenocarcinoma, followed by undifferentiated and squamous cell carcinoma. These data are in agreement with the findings of Ford $e t a l^{9}$ and Pascal et $a l^{18}$ who observed a higher incidence of increased CEA in adenocarcinoma of the lung than in other histological types. Pascal has suggested that this results in part from the fact that undifferentiated and squamous tumours of the lung lose the ability to secrete oncofetal antigen through malignant cellular differentiation, while in contrast adeno- carcinoma retains its morphological endodermal characteristics and CEA secretion. This hypothesis is appealing and merits further immunochemical investigation.

This study demonstrates that bronchial tumours secrete carcinoembryonic antigen preoperatively in amounts that correlate well with the clinical tumour burden as defined by postsurgical staging methods. Of the histological types of bronchial carcinoma studied, adenocarcinoma produced this glycoprotein most frequently, reflecting, perhaps, its origin from the endodermally derived bronchial mucosa cells. Although not specific enough for screening purposes, CEA has clinical potential as a biological tumour marker in the management of bronchial neoplasms. In our current studies, preoperative CEA determinations are obtained along with sequential postoperative levels after pulmonary resection in patients with bronchial carcinoma. The pattern of CEA elevations observed in this setting may be of great benefit in the determination of prognosis, the definition of extent of disease for adjuvant therapy, and as a means of surveillance for recurrent carcinoma after operation.

We are grateful for the advice and support of Mr DM Milne and Mr G Keen of the Department of Thoracic Surgery, Frenchay Hospital, Bristol, and we are indebted to Professor KD Bagshawe of the Department of Medical Oncology, Charing Cross Hospital, London, for his critical review of this manuscript.

\section{References}

1 Lo Gerfo P, Krupey J, Hansen HJ. Demonstration of an antigen common to several varieties of neoplasia. Assay using zirconyl phosphate gel. $N$ Engl J Med 1971; 285:138-41.

2 Laurence DJR, Stevens U, Bettelheim R et al. Role of plasma carcinoembryonic antigen in diagnosis of gastrointestinal, mammary, and bronchial carcinoma. Br Med J 1972; 3:605-9.

3 Vincent RG, Chu TM. Carcinoembryonic antigen in patients with carcinoma of the lung. $J$ Thorac Cardiovasc Surg 1973; 66:320-8.

4 Concannon JP, Dalbow MH, Liebler GA, Blake KE, Weil CS, Cooper JW. The carcinoembryonic antigen assay in bronchogenic carcinoma. Cancer 1974; 34:184-92.

5 Pauwels R, Van der Straten M. Plasma levels of carcinoembryonic antigen in bronchial carcinoma and chronic bronchitis. Thorax 1975; 30:560-2.

6 Concannon JP, Dalbow MH, Hodgson SE et al. Prognostic value of preoperative carcinoembryonic antigen (CEA) plasma levels in patients 
with bronchogenic carcinoma. Cancer (Suppl) 1978; 42:1477-83.

7 Dent PB, McCulloch PB, Wesley-James O, MacLaren R, Muirhead W, Dunnett CW. Measurement of carcinoembryonic antigen in patients with bronchogenic carcinoma. Cancer (Suppl) 1978; 42:1484-91.

8 Vincent RG, Chu TM, Lane WW, Gutierrez AG, Stegemann PJ, Madajewicz S. Carcinoembryonic antigen as a monitor of successful surgical resection in 130 patients with carcinoma of the lung. J Thorac Cardiovasc Surg 1978; 75:734-9.

9 Ford CHJ, Newman CE, Lakin J. Role of carcinoembryonic antigen in bronchial carcinoma. Thorax 1977; 32:582-8.

10 Kardana A, Squires M, Adams T, Goka GK, Bagshawe KD. Sensitive radioimmunoassays using partially purified gamma globulins coupled to Enzacryl (acrilamide polymer) solid support. J Immunol Methods 1980; in press.

11 Keep PA, Leake BA, Rogers GT. Extraction of CEA from tumour tissue, foetal colon and patients sera, and the effect of perchloric acid. Br J Cancer 1978; 37:171-82.

12 Beahrs OH, Carr DT, Rubin P. In: Manual for Staging of Cancer. American Joint Committee for Cancer Staging and End-Results Reporting. Chicago, Illinois: Whiting Press, 1978.

13 Gropp C, Havemann K, Lehmann F-G. Carcinoembryonic antigen and ferritin in patients with lung cancer before and during therapy. Cancer 1978; 42:2802-8.

14 Tormey DC, Waalkes TP, Ahmann D et al. Biological markers in breast carcinoma I. Incidence of abnormalities of CEA, HCG, three polyamines, and three minor nucleosides. Cancer 1975; 35:1095-100.

15 Vincent RG, Chu TM, Fergen TB, Ostrander M. Carcinoembryonic antigen in 228 patients with carcinoma of the lung. Cancer 1975; 36:2069-76.

16 Martini N, Beattie EJ. Results of surgical treatment in Stage I lung cancer. $J$ Thorac Cardiovasc Surg 1977; 74:499-505.

17 Naruke T, Suemasu K, Ishikawa S. Lymph node mapping and curability at various levels of metastasis in resected lung cancer. $J$ Thorac Cardiovasc Surg 1978; 76:832-9.

18 Pascal RR, Mesa-Tejada R, Bennett SJ, Garces A, Fenoglio CM. Carcinoembryonic antigen. Immunohistologic identification in invasive and intraepithelial carcinomas of the lung. Arch Pathol Lab Med 1977; 101:568-71. 